\title{
GRAIN SIZE STATISTICAL PARAMETERS AND PALAEOFLOW VELOCITY MEASUREMENTS OF THE TERTIARY PINDOS FORELAND BASIN TURBIDITES
}

\author{
Vakalas I., Ananiadis G., Kontopoulos N. and Zelilidis A. \\ Laboratory of Sedimentology, Department of Geology, University of Patras, 26500, Rio, Patras, \\ Greece, ivakalas@upatras.gr, gananiad@upatras.gr, Kontopou@upatras.gr, \\ a.zelilidis@upatras.gr
}

\begin{abstract}
Pindos foreland is a tertiary turbiditic basin fill trending parallel to the external Hellenides (Aubouin, 1959). The basin is bounded to the east by the Pindos thrust and to the west by the lonian thrust. Apart of these two major thrusts, minor thrusts separate the basin into linear narrow sub-basins, trending also parallel to the basin axis.

For the grain size statistical analysis 35 sandstone samples were collected from sandstone beds in three sections: Metsovo, Amphilochia and Palaiopyrgos. The thickness of the beds ranges from 8 to $25 \mathrm{~cm}$, and comprise Ta, Tb and Tc Bouma sequence subdivisions. The samples were smashed in small pieces and then they were disaggregated using acetic acid solution. Then the samples were washed with deionized water and prepared for sieve analysis. The results of the sieve analysis were plotted in grain size cumulative diagrams in order to estimate the statistical parameters. Sorting, skewness and kyrtosis were calculated and also the samples were plotted in CM, FM and LM diagrams (Passega, 1957; Passega, 1964) The palaeoflow velocity measurements were estimated using Komar's model (1985).

The results of the above analysis provided the following conclusions: a) Sorting values are decreasing at the top of Metsovo and Palaiopyrgos sections indicating an increase of the sediments immaturity. b) The asymmetry values range from positive to very positive with a trend to increase at he top in the sections of Metsovo and Amphilochia, which shows a dominance of the coarser fraction in the selected samples, c) C-M, F-M, L-M affirms that the sediment was transported to the deeper parts of the basin by turbidity currents.

Mean flow velocities at the time of deposition range between 1,86 and $26,59 \mathrm{~cm} / \mathrm{sec}$. These values are very much in agreement with those proposed for low-density turbidity currents $(<25 \mathrm{~cm} / \mathrm{sec}$ ) (Nelson and Nilsen, 1984). A similar velocity range is refereed also by Avramidis (1999) who studied the turbidites of the Middle Ionian zone. In Metsovo and Palaiopyrgos mean flow velocity values increase towards the top of the stratigraphy.
\end{abstract}

\section{GEOLOGICAL SETTING}

The study area is part of the Pindos foreland (Underhill, 1985) and comprises Epirus, Akarnania and NW Peloponnesus regions. Pindos foreland is a tertiary turbiditic foreland basin fill trending parallel to the external Hellenides and occupies Gavrovo and Ionian isopic zones (Aubouin, 1959). The basin is bounded to the east by the Pindos thrust and to the west by the lonian thrust. The Gavrovon thrust separates the Gavrovo and Internal Ionian zones. Apart of these major thrusts, two minor thrusts divide the Ionian zone into the internal, middle and external Ionian zone (from east to the west) (IGSR\&IFP, 1966).

The accumulation of the turbiditic deposits resulted from the deformation of the external Hellenides which migrated westwards. During this migration the Gavrovo and Ionian zones acted as a foreland basin (Underhill 1985, Brooks et al 1988, Underhill 1989, Clews 1989, Alexander et al 
1990, Avramidis 1999). Therefore the turbiditic deposits of Gavrovo and Internal Ionian zones are considered as a uniform genetic system (Jenkins 1979, Alexander et al 1990).

Interpretation of palaeocurrent data and facies distributions (B.P. 1970, Piper et al 1978, Alexander et al 1990) indicates that the provenance of Pindos foreland turbiditic deposits is the Pindos thrust belt to the east. According to Leygh et al (1991) a major source of sediment was located in the area which today represents the gulf of Patras. Flow within the basin was axial (Leygh, 1991).

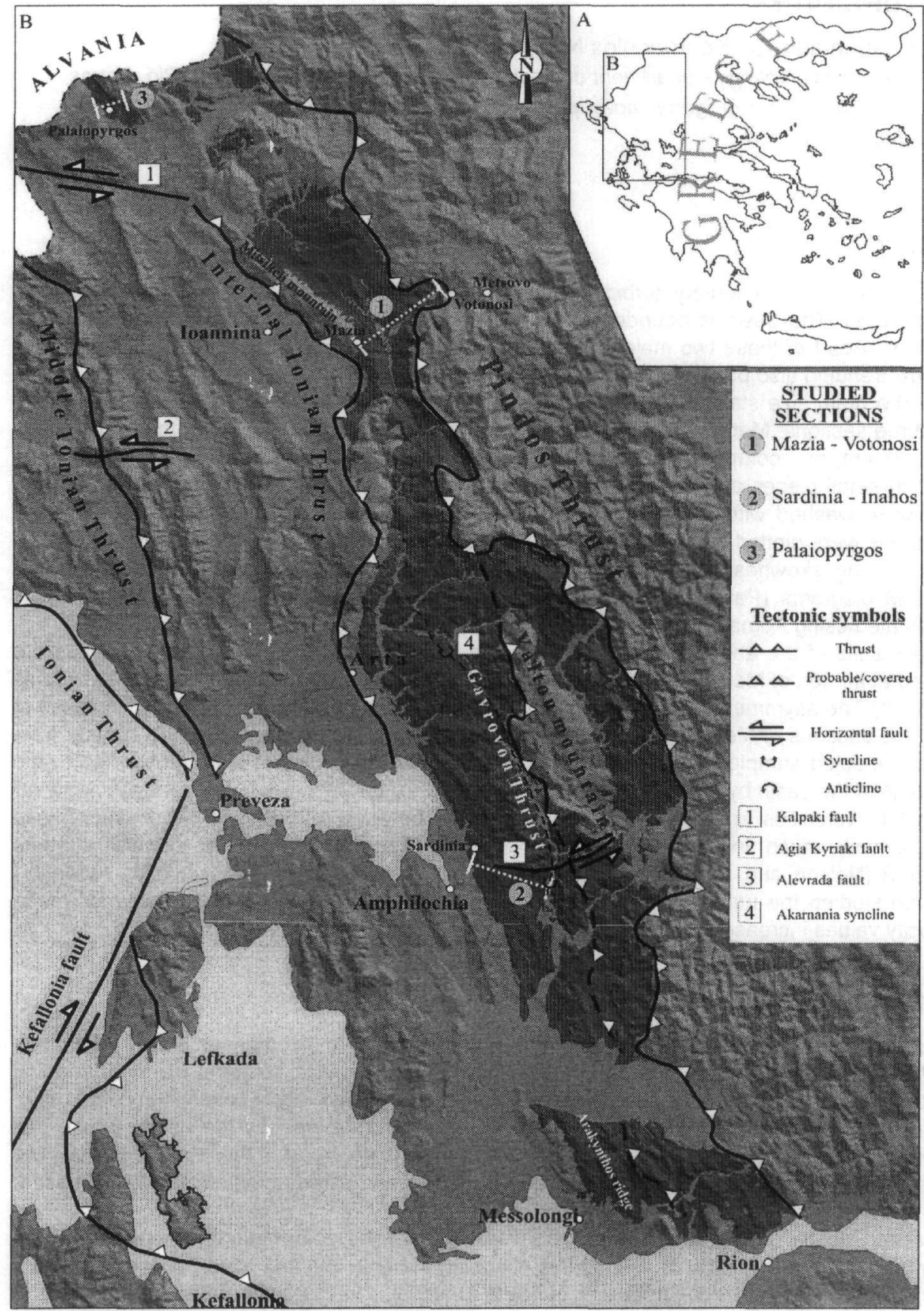

Figure 1: Simplified geological map of the study area. 


\section{METHODOLOGY}

Thirty-five sandstone samples were selected from two major an one minor sections across the Internal Ionian zone turbidites. The first section is located at the national road loannina-Metsovo and ranges from Mazia to Votonosi villages. The second section is located to the road SardiniaInahos river eastwards of Amphilochia. Eleven and fifteen samples were collected from these two sections respectively. Also, 7 samples were studied originating from turbidite deposits near the Hellenic-Albanian borders. Samples cover a wide range of the exposed stratigraphy, from the base to the top of each section. The average thickness of the sandstone beds that the samples came from was $14.2 \mathrm{~cm}$ and the standard deviation $5.1 \mathrm{~cm}$. The collected samples were smashed into pieces which diameter doesn't exceeds $5 \mathrm{~mm}$. Smashing force was applied parallel to bedding in order to reduce the destruction of grain's shape, and never were used a grinding motion. A hundred grams from each sample were added to a $30 \%$ acetic acid solution and then heated in a heating source at the temperature of $700 \mathrm{C}$. The use of the acetic acid allows the destruction of the calcite matrix and the release of the grains (disaggragetion). The renewal of the acetic acid solution increased the speed of the chemical reaction. When the boiling stopped, each sample was washed with diionized water three times and put into a new solution of $30 \%$ hyperoxide of hydrogene. The solution was again heated until the soluble mean evaporated. The sediment was again washed with diionized water for three times and let to dry. About $85 \%-100 \%$ of each sample was disaggregated using this method (Carver, 1971). Finally grain size distributions were made using sieve and pipette analysis results.

\section{GRAIN SIZE STATISTICAL PARAMETERS}

Calculation of grain size parameters such as mean, median, sorting, skewness and kyrtosis was based using Folk and Ward (1957) equations. The results for each section are shown at the following tables:

Table 1: Grain size parameters of loannina-Metsovo section.

\begin{tabular}{|c|c|c|c|c|c|}
\hline Sample & Median & Mean & Sorting & Skewness & Name \\
\hline MB1 & 3,52 & 3,53 & 1,24 & 0,17 & Silty sand \\
MB2 & 3,87 & 4,00 & 1,82 & 0,27 & Silty sand \\
MB3 & 3,89 & 3,91 & 1,62 & 0,15 & Silty sand \\
MB7 & 3,17 & 3,42 & 1,58 & 0,42 & Silty sand \\
MB8 & 3,32 & 3,56 & 1,45 & 0,41 & Silty sand \\
MB9 & 3,25 & 3,41 & 1,84 & 0,34 & Silty sand \\
MB10 & 2,84 & 3,14 & 1,82 & 0,56 & Silty sand \\
MB11 & 2,89 & 3,28 & 2,01 & 0,52 & Silty sand \\
MB12 & 2,98 & 3,25 & 2,02 & 0,40 & Silty sand \\
MB14 & $\mathbf{2 , 7 8}$ & $\mathbf{3 , 1 1}$ & $\mathbf{1 , 9 4}$ & $\mathbf{0 , 4 9}$ & Silty sand \\
\hline
\end{tabular}

Table 2: Grain size parameters of Palaiopyrgos section.

\begin{tabular}{|c|c|c|c|c|c|}
\hline Sample & Median & Mean & Sorting & Skewness & Name \\
\hline AL7 & 3,81 & 3,90 & 1,07 & 0,35 & Silty sand \\
AL1 & 4,64 & 4,87 & 1,32 & 0,44 & Silty sand \\
AL2 & 3,94 & 3,95 & 1,40 & 0,21 & Sandy silt \\
AL3 & 3,88 & 3,88 & 1,16 & 0,23 & Silty sand \\
AL6 & 3,58 & 3,71 & 1,31 & 0,36 & Silty sand \\
AL4 & 3,38 & 3,41 & 1,74 & 0,27 & Silty sand \\
AL5 & $\mathbf{2 , 8 5}$ & $\mathbf{3 , 1 5}$ & $\mathbf{1 , 9 9}$ & $\mathbf{0 , 3 6}$ & Silty sand \\
\hline
\end{tabular}


Table 3: Grain size parameters of Sardinia - Inahos section.

\begin{tabular}{|c|c|c|c|c|c|}
\hline Sample & Median & Mean & Sorting & Skewness & Name \\
\hline AMF1 & 2,79 & 3,10 & 1,67 & 0,44 & Silty sand \\
AMF3 & 2,97 & 3,37 & 1,79 & 0,50 & Silty sand \\
AMF4 & 3,89 & 3,94 & 1,23 & 0,20 & Silty sand \\
AMF5 & 2,88 & 3,06 & 1,25 & 0,24 & Silty sand \\
AMF6 & 2,92 & 3,10 & 1,54 & 0,35 & Silty sand \\
AMF7 & 3,93 & 4,37 & 1,46 & 0,73 & Silty sand \\
AMF8 & 3,68 & 3,94 & 1,29 & 0,66 & Silty sand \\
AMF9 & 3,44 & 3,63 & 1,22 & 0,62 & Silty sand \\
AMF10 & 3,77 & 3,95 & 1,28 & 0,62 & Silty sand \\
AMF11 & 3,56 & 3,70 & 1,17 & 0,60 & Silty sand \\
AMF12 & 3,73 & 4,08 & 1,30 & 0,71 & Silty sand \\
AMF13 & 3,63 & 3,73 & 1,00 & 0,58 & Silty sand \\
AMF15 & 3,74 & $\mathbf{4 , 1 3}$ & 1,51 & 0,70 & Silty sand \\
AMF17 & 3,24 & 3,51 & 1,33 & 0,66 & Silty sand \\
AMF18 & $\mathbf{3 , 6 9}$ & $\mathbf{4 , 1 3}$ & $\mathbf{1 , 6 6}$ & $\mathbf{0 , 7 1}$ & Silty sand \\
\hline
\end{tabular}

According to the above tables it is concluded that:

i. Sorting values range from 1.24 to 2.01 in loannina-Metsovo section, 1.00 to 1.79 in Sardinia-Inahos section and 1.07 to 1.99 in Palaiopyrgos section. These values characterize poorly sorted deposits according to Folk \& Ward (1957). Also at the upper stratigraphic levels a decrease of sorting in all the sections, which is in consistency with the presence of a more proximal environment at these levels (Vakalas, 2003), were sediments are immature.

ii. Skewness values range from 0.15 to 0.62 in loannina-Metsovo section, $0.20-0.73$ in Sardinia-Inahos section and $0.21-0.44$ in Palaiopyrgos section. According to Folk \& Ward (1957) the samples are fine to strongly fine-skewed. Sedimentoligically this skewness indicate that the most abundant size material in the samples is coarse, but some $50 \%$ of the material is relatively fine (Excess fine particles) (Friedman \& Johnson, 1982). Moreover, the positive skewness is due to the competency of the unidirectional flow of the transporting media where the coarse end of the size frequency curve is "chopped of" (Friedman, 1961, 1962, 1979). Analogous conditions prevail during the turbidity deposition.

\section{$4 \mathrm{CM}, \mathrm{FM}, \mathrm{LM}$ DIAGRAMS}

In order to affirm the flow type that transported the sediment to the basin, the samples were plotted at CM, FM and LM diagrams proposed by Passega (1957, 1964).

Almost all of the samples in the CM diagram (figure 2) (C: $1^{\text {st }}$ percentile of the cumulative grain size diagram and $\mathrm{M}$ : mean) are plotted at 5 and 7 fields. These fields suggest transportation under a graded suspension regime. Also, these samples are inside or near the field, which corresponds to transportation by turbidity currents.

In F-M and L-M diagrams, $\mathrm{F}$ and $\mathrm{L}$ axes correspond to the percentage by weight of each sample, which is thinner than 125 and $31 \mu \mathrm{m}$ respectively. The $M$ axis represents the mean grain size of each sample. The shape of the trend line drawn for each diagram is characteristic for the type of flow, which transports the sediment. In the next figure (figure 3) F-M and L-M diagrams for each section are shown. 


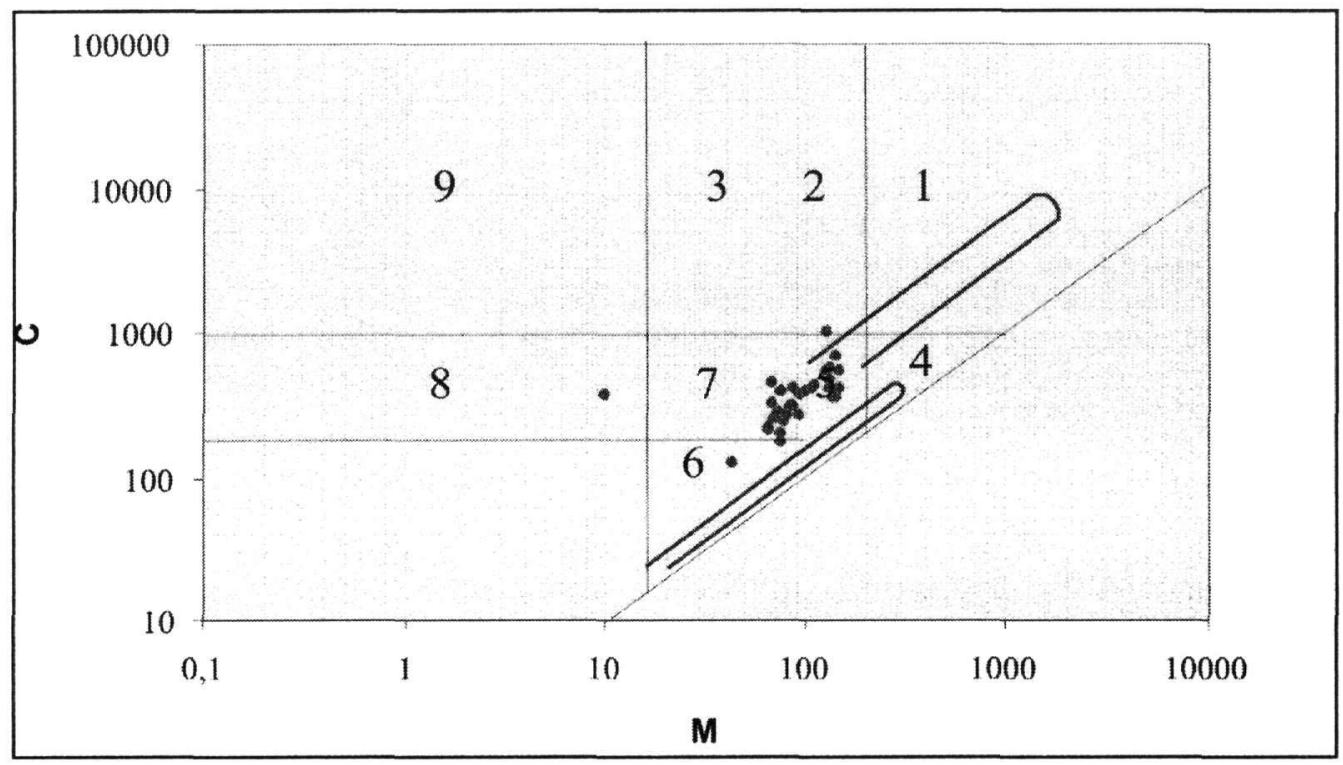

Figure 2: C-M diagram of the examined samples. The bold black curves represent turbidite fields that are proposed by Passega (1957). Turbidite fields were confirmed by Passega who studied turbidite deposits in Apennina (Italy).

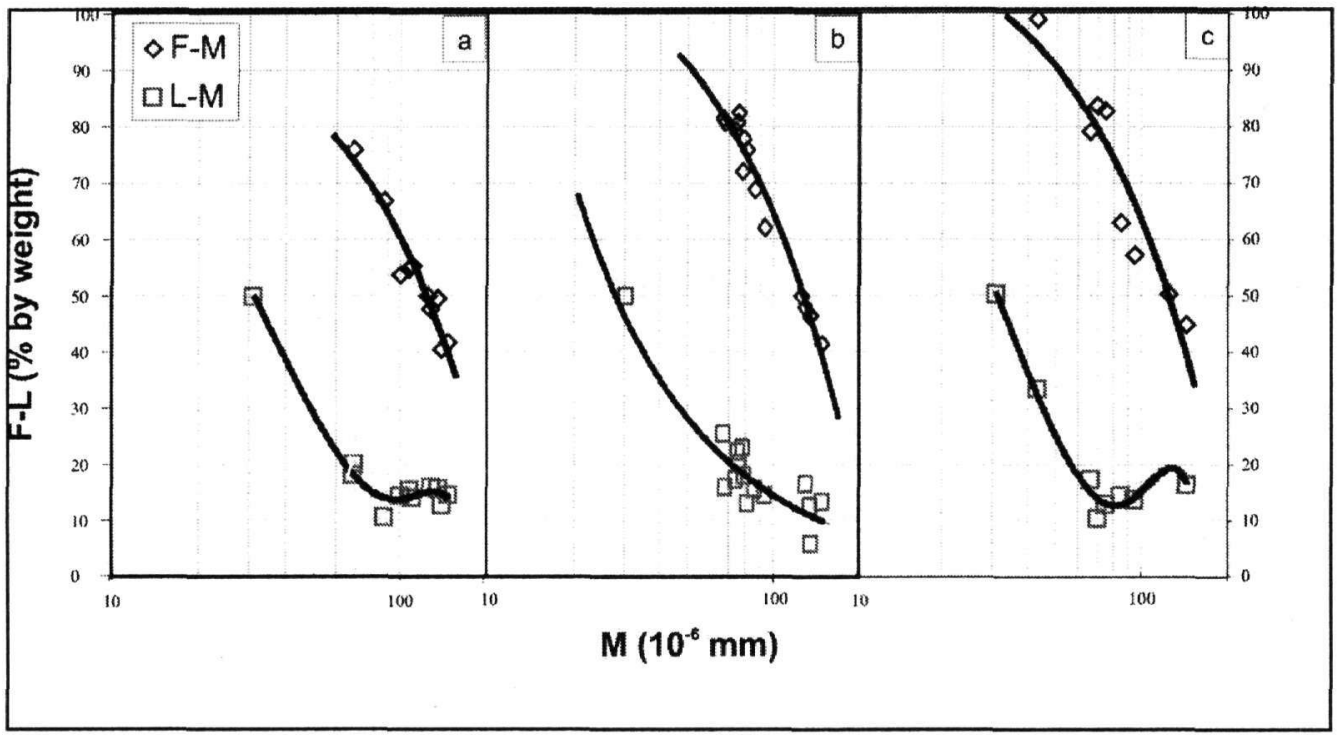

Figure 3: F-M, L-M diagram of the examined samples. The bold black curves represent the trend lines of the examined samples. A) loarnina-Metsovo section B) Sardinia-Inahos section C) Palaiopyrgos section.

\section{MEAN FLOW VELOCITY ESTIMATION}

The estimation of mean flow velocity during deposition was based at Komar's (1985) hydraulic model. According to this model the mean flow velocity during deposition is given by the following equation (1): 


$$
\bar{u}=\frac{W_{m}}{\sqrt{C_{f}}}
$$

where $\bar{u}$ is the mean flow velocity during deposition, $\mathrm{Wm}$ is the settling velocity of the $50^{\text {th }}$ percentile and $\mathrm{C}_{f}$ is a dimensionless drag coefficient. Cf value is 0.004 as proposed by Komar (1985).

The calculation of settling velocity $(\mathrm{Wm})$ took place at two steps. The first step was the convertion of the grain diameters, which were used in the cumulative grain size diagrams, into settling velocities according to Rubey's formula (1933). The second step was the construction of the cumulative hydraylic curves, based on the scale Psi $=-\log _{2}(\mathrm{Wm})$ proposed by Middleton (1967). Using these curves, by converting Psiso percentile values to settling velocities $(\mathrm{Wm})$, according to Middleton's scale, mean flow velocity can be estimated considering equation 1.

At the following tables (tables $4,5,6$ ) mean flow velocity values, as well as sample characteristics such as bed thickness and Bouma divisions are shown. The first row of each table corresponds to the stratigraphically lower sample, while the last to the upper.

Table 4: Mean flow velocity values (ū) in loannina-Metsovo section. Bed thickness and Bouma divisions are also shown, as well as the settling velocity $(\mathrm{Wm})$ and the Psi ${ }_{50}$ values of the cumulative hydraulic curves.

\begin{tabular}{|c|c|c|c|c|c|}
\hline Sample & Bed thickness & Bouma Division & Psi $(50 \%)$ & Wm & $\Theta(\mathrm{cm} / \mathrm{sec})$ \\
\hline MB1 & $26 \mathrm{~cm}$ & $\mathrm{Ta}$ & 0,645 & 0,64 & 10,11 \\
MB2 & $14 \mathrm{~cm}$ & $\mathrm{~Tb}(8 \mathrm{~cm}), \mathrm{Tc}(6 \mathrm{~cm})$ & 1,420 & 0,37 & 5,91 \\
MB3 & $11 \mathrm{~cm}$ & $\mathrm{~Tb}(4 \mathrm{~cm}), \mathrm{Tc}(7 \mathrm{~cm})$ & 1,450 & 0,37 & 5,79 \\
MB7 & $20 \mathrm{~cm}$ & $\mathrm{~Tb}(10 \mathrm{~cm}), \mathrm{Tc}(10 \mathrm{~cm})$ & $-0,047$ & 1,03 & 16,33 \\
MB8 & $20 \mathrm{~cm}$ & $\mathrm{Ta} ?$ & 0,234 & 0,85 & 13,44 \\
MB9 & $9 \mathrm{~cm}$ & $\mathrm{Ta}$ & 0,080 & 0,95 & 14,96 \\
MB10 & $15 \mathrm{~cm}$ & $\mathrm{Ta}$ & $-0,650$ & 1,57 & 24,81 \\
MB11 & $12 \mathrm{~cm}$ & $\mathrm{Ta}$ & $-0,563$ & 1,48 & 23,36 \\
MB12 & $24 \mathrm{~cm}$ & $\mathrm{Ta}(10 \mathrm{~cm}), \mathrm{Tc}(14 \mathrm{~cm})$ & $-0,475$ & 1,39 & 21,98 \\
MB14 & $9 \mathrm{~cm}$ & $\mathrm{Ta}$ & $-0,750$ & 1,68 & 26,59 \\
\hline
\end{tabular}

Table 5: Mean flow velocity values (ü) in Sardinia-Inahos section.

\begin{tabular}{|c|c|c|c|c|c|}
\hline Sample & Bed thickness & Bouma Division & Psi $(50 \%)$ & Wm & (cm/sec) \\
\hline AMB1 & $150 \mathrm{~cm}$ & $\mathrm{~Tb}$ & $-0,750$ & 1,68 & 26,59 \\
AMB3 & $22 \mathrm{~cm}$ & $\mathrm{Ta}$ & $-0,475$ & 1,39 & 21,98 \\
AMB4 & $13 \mathrm{~cm}$ & $\mathrm{Ta}(8 \mathrm{~cm}), \mathrm{Tb}(2 \mathrm{~cm}), \mathrm{Tc}(3 \mathrm{~cm})$ & 1,431 & 0,37 & 5,86 \\
AMB5 & $16 \mathrm{~cm}$ & $\mathrm{Ta}$ & $-0,606$ & 1,52 & 24,07 \\
AMB6 & $17 \mathrm{~cm}$ & $\mathrm{Ta}$ & $-0,567$ & 1,48 & 23,42 \\
AMB7 & $10 \mathrm{~cm}$ & $\mathrm{Ta}(4,5 \mathrm{~cm}), \mathrm{Tb}(3 \mathrm{~cm}), \mathrm{Tc}(2,5 \mathrm{~cm})$ & 1,514 & 0,35 & 5,54 \\
AMB8 & $10 \mathrm{~cm}$ & $\mathrm{Ta}$ & 0,967 & 0,51 & 8,09 \\
AMB9 & $10 \mathrm{~cm}$ & $\mathrm{Ta}$ & 0,424 & 0,75 & 11,79 \\
AMB10 & $10 \mathrm{~cm}$ & $\mathrm{Ta}(4,5 \mathrm{~cm}), \mathrm{Tb}(5,5 \mathrm{~cm})$ & 1,180 & 0,44 & 6,98 \\
AMB11 & $15 \mathrm{~cm}$ & $\mathrm{Ta}$ & 0,684 & 0,62 & 9,84 \\
AMB12 & $15 \mathrm{~cm}$ & $\mathrm{Ta}$ & 1,078 & 0,47 & 7,49 \\
AMB13 & $12,5 \mathrm{~cm}$ & $\mathrm{Ta}$ & 0,870 & 0,55 & 8,65 \\
AMB15 & $8 \mathrm{~cm}$ & $\mathrm{Ta}$ & 1,110 & 0,46 & 7,33 \\
AMB17 & $10 \mathrm{~cm}$ & $\mathrm{Ta}$ & 0,040 & 0,97 & 15,38 \\
AMB18 & $13 \mathrm{~cm}$ & $\mathrm{Ta}$ & 1,010 & $\mathbf{0 , 5 0}$ & 7,85 \\
\hline
\end{tabular}


Table 6: Mean flow velocity values (ū) in Palaiopyrgos section.

\begin{tabular}{|c|c|c|c|c|c|}
\hline Sample & Bed thickness & Bouma Division & Psi $(50 \%)$ & Wm & (cm/sec) \\
\hline AL7 & $10 \mathrm{~cm}$ & Ta $(5 \mathrm{~cm}), \mathrm{Tc}(5 \mathrm{~cm})$ & 1,254 & 0,42 & 6,63 \\
AL1 & $10 \mathrm{~cm}$ & Tc & 3,090 & 0,12 & 1,86 \\
AL2 & $8 \mathrm{~cm}$ & Tc & 1,550 & 0,34 & 5,40 \\
AL3 & $25 \mathrm{~cm}$ & Tc & 1,420 & 0,37 & 5,91 \\
AL6 & $11 \mathrm{~cm}$ & Ta & 0,755 & 0,59 & 9,37 \\
AL4 & $12 \mathrm{~cm}$ & Ta & 0,349 & 0,79 & 12,41 \\
AL5 & $\mathbf{2 4 c m}$ & Ta & $-\mathbf{0 , 6 5 5}$ & $\mathbf{1 , 5 7}$ & 24,90 \\
\hline
\end{tabular}

Considering tables 4, 5, 6 it is concluded that:

i. Mean flow velocity values in Ioannina-Metsovo section ranges from 5.79 to $26.59 \mathrm{~cm} / \mathrm{sec}$. An increase in velocity values is noticed passing from the lower to the upper stratigraphic levels.

ii. In Sardinia-Inahos section mean flow velocity values range from 1.86 to $26.59 \mathrm{~cm} / \mathrm{sec}$. Increased velocity values have been noticed at the lower and middle stratigraphic levels. At the upper stratigraphic levels flow velocity values do not exceed $15.38 \mathrm{~cm} / \mathrm{sec}$.

iii. In Palaiopyrgos section flow velocities are decreased in comparison with those estimated at the two previous sections, except sample AL5 $(24.90 \mathrm{~cm} / \mathrm{sec})$. Flow velocity at the rest of the samples is below $12.41 \mathrm{~cm} / \mathrm{s} \in \mathrm{C}$. Also, an increase of flow velocity values is noticed moving upwards the stratigraphy.

\section{CONCLUSIONS}

The results of the above analysis provided the following conclusions:

1. Sorting values are decreasing (more poorly sorted sediments) at the top of Metsovo and Palaiopyrgos sections indicating an increase of the sediments immaturity. This is in convention with the general pattern of the progradation of more proximal settings as we move upwards the stratigraphy. A different view nas been observed in the lower part of Amphilochia section, where two samples originating from the lower stratigraphic levels showed decreased sorting in comparison with the underlying deposits. This can be explained taking under consideration that the deposits at this level of the stratigraphy belong to an inner fan environment.

2. The skewness values range from fine to strongly-fine with a trend to increase at he top in the sections of Metsovo and Amphilochia, which shows a turbidity character of deposition.

3. C-M, F-M, L-M affirms that the sediment was transported to the deeper parts of the basin by turbidity currents.

4. Mean flow velocities at the time of deposition range between 1,86 and $26,59 \mathrm{~cm} / \mathrm{sec}$. These values are very much in agreement with those proposed for low-density turbidity currents $(<25 \mathrm{~cm} / \mathrm{sec}$ ) (Nelson \& Nilsen, 1984). The characterization of the currents as "low density currents" it is also supported by Pickering's classification, which was used for the fieldwork. A similar velocity range is refereed also by Avramidis (1999) and Avramidis \& Kontopoulos (1998) who studied the turbidites of the Middle Ionian zone.

5. In Metsovo and Palaiopyrgos mean flow velocity values increase towards the top of the stratigraphy. This also supports the progradation of proximal environments, where the gradient of the sea bottom and the energy of the system are higher. In Amphilochia section the higher mean flow velocity values have been observed at the lower and middle stratigraphic levels.

\section{REFERENCES}

Aubouin J., 1959. Contribution à l'étude géologique de la Grèce Septentrionale. Les confines de l'Epire et de la Thessalie, Ann. Geol. d. Pays Helen. 10,1-525, Athènes

Avramidis P., 1999. Depositional environments and hydrocarbon potential of Tertiary formations in Klematia-

Paramythia basin, Epirus, PhD thesis, University of Patras.

Avramidis P. \& Kontopoulos N. (1998) Hydraulic determination and palaeoflow trends of turbidite deposits in Klematia - Paramythia basin, Bulletin of the Geological Society of Greece, XXXII/2, 299-307 
Carver, R.E. (1971) Procedures in Sedimentary Petrology. Wiley-Interscience, New York, 653p.

Folk R.L., \& Ward W.C. (1957) Brazos river bar: a study of significante of grain size parameters. J. Sediment. Petrol. 27, 3-26.

Friedman, G.M. (1961) Distribution between dune, bech and river sands from their textural characteristics. J.Sed.Petr., 31, 514-529.

Friedman, G.M. (1962) On sorting, sorting coeflicients, and the lognormality of the grain-size distribution of sandstones. J. Geoll., 70, 737-753.

Friedman, G.M. (1979) Differences in size distributions of populations of particles among sands of varions origins: Addendum to IAS Presidential Address. Sedimentology, 26, 859-862.

Friedman, G.M. \& Johnson, K.G. (1982) Exercises in Sedimentology. J.Wiley \&Sons, New York, 208p.

Komar, P. D. (1985) The hydraulic interpretation of turbidites from their grain sizes and sedimentary structures. Sedimentology, 32, 395-407.

Middleton, G.V. (1967) Experiments on density and turbidity currents. III. Deposition of sediments. Can. J. Earth Sc., 4, 475-505.

Nelson C.H. \& Nilsen T.H., 1984. Modern and ancient deep-sea fan sedimentation. Soc. Econ. Paleontol. Mineral., Short course, 14.

Passega R., 1957. Texture as characteristic of clastics deposition: Am. Soc. Asoc. Petrol. Geol. Bull. Tulsa, Okland, 41, 1952-1984.

Passega R., 1964. Grain size representation by CM patterns as a geologic tool: Jour. Sed. Petrol. Tulsa Ok., 34, No. $4,830-847$.

Nelson, C.H. \& Nilsen, T.H. (1984) Modern and ancient deep-sea fan sedimentation. Soc. Econ. Paleontol. Mineral., Short course, 14 .

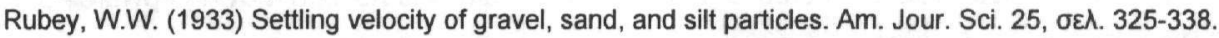

Vakalas I. (2003) The Evolution of Foreland Basins in Western Greece, Ph.D thesis, University of Patras 